BRAVILLIAN JOURNAL

www.bjournal.com.br
ISSN 0100-879X

Volume 44 (8) 729-813 August 2011

BIOMEDICAL SCIENCES

AND

CLINICAL INVESTIGATION

Braz J Med Biol Res, August 2011, Volume 44(8) 748-753

doi: 10.1590/S0100-879X2011007500080

Modulation of murine blastocyst hatching in vitro by glutamine and tryptophan

W. Castro, J.C. Bueno Sánchez, C. Piedrahita-Ochoa and A.P. Cadavid J.

The Brazilian Journal of Medical and Biological Research is partially financed by

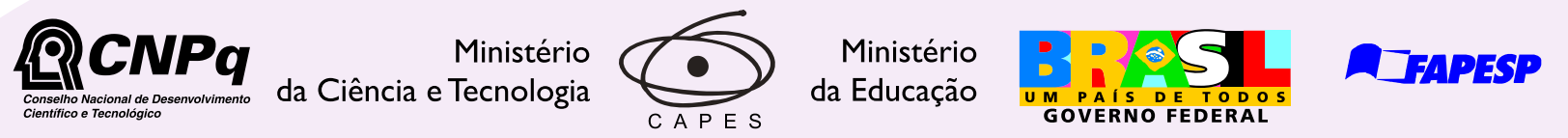

Institutional Sponsors
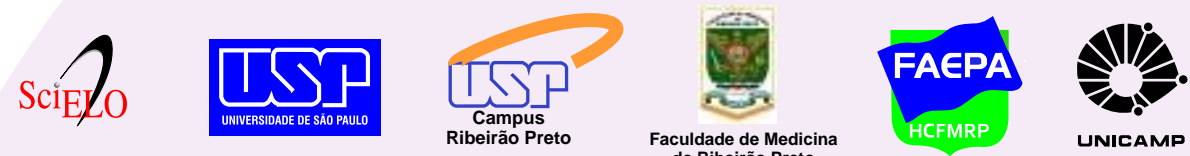

Ф SHIMADZU

Explore High - Performance MS Orbitrap Technology In Proteomics \& Metabolomics

\section{analitica Thermo}




\title{
Modulation of murine blastocyst hatching in vitro by glutamine and tryptophan
}

\author{
W. Castro, J.C. Bueno Sánchez, C. Piedrahita-Ochoa and A.P. Cadavid J. \\ Grupo Reproducción, Sede de Investigación Universitaria, Universidad de Antioquia, Medellín, Colombia
}

\begin{abstract}
Enrichment of culture media with amino acids improves embryo development. However, little is known about the specific action of each amino acid during embryogenesis. The present study was undertaken to examine the effect of L-glutamine (GIn) and tryptophan (Trp) on mouse embryo hatching, expansion and viability in vitro. Blastocysts were collected from 6- to 8-week-old female BALB/c mice $(\mathrm{N}=30)$ and cultured in M2 medium containing either $0.125,0.25$ or $0.5 \mathrm{mM}$ Trp, $1 \mathrm{mM}$ Gln, or M2 alone. Gln significantly increased (100\%; P < 0.05) blastocyst hatching at $24 \mathrm{~h}$ compared to M2 alone or Trp; moreover, Trp inhibited blastocyst hatching when compared to $\mathrm{M} 2$ alone $(\mathrm{P}<0.05)$ at $72 \mathrm{~h}$. In contrast, the percentage of embryos reaching the state of expanded blastocyst at $48 \mathrm{~h}$ was significantly higher in medium with $1 \mathrm{mM}$ GIn $(66.6 \% ; \mathrm{P}<0.05)$ or with $0.125 \mathrm{mM} \mathrm{Trp}(61.1 \%$; $\mathrm{P}<0.05)$. Unexpectedly, Trp increased the percentage of degenerated blastocysts after $48 \mathrm{~h}(67.7 \%$; $\mathrm{P}<0.05)$, while Gln preserved blastocyst viability. These results suggest that GIn may enhance blastocyst hatching, expansion and viability in vitro.
\end{abstract}

Key words: Embryo development; Murine blastocyst; Hatching; Glutamine; Tryptophan

\section{Introduction}

Prior to implantation, blastocyst hatching from the zona pellucida (ZP) must occur for the attachment of the blastocyst to the endometrial epithelium and penetration towards the endometrium. Typically, hatching involves blastocyst expansion that causes thinning of the ZP and the synthesis of trypsin-like proteinases by cells of the trophoectoderm. This subsequently induces rupture of the ZP at different sites (1).

The use of amino acids has been the subject of several studies aimed at designing an appropriate culture medium whose composition would improve embryo development in vitro. Poor-quality embryos result from suboptimal in vitro culture conditions, and under these circumstances only a small proportion of embryos reach the hatched blastocyst stage. Even if culture conditions are sufficient, failure to hatch may be due to the hardening of the ZP and other intrinsic factors (2). For this reason, it was suggested that supplementation of the culture medium with amino acids might improve blastocyst formation. Nevertheless, no studies have been conducted to determine the action of specific amino acids on hatching embryos and the use of L-glutamine (GIn) as a supplement for the culture of embryos is controversial. Rezk et al. (3) demonstrated that Gln increases the number of embryos that reach the blas- tocyst stage. However, according to Devreker and Hardy (4), addition of GIn to the culture decreases the number of cells of the trophoectoderm and the inner cell mass (ICM). Other studies have reported that GIn supplementation in the culture medium has no effect $(5,6)$. Although this controversy remains, we hypothesized that GIn may improve blastocyst hatching in vitro, and we established an artificial model to test whether a single amino acid would affect embryo development.

L-tryptophan (Trp) is emerging as an important amino acid for the development of the blastocyst. The absence of Trp in the medium for embryos grown in vitro had a significant impact on processes such as hatching, adhesion to a collagen matrix and embryo outgrowth (7). Tryptophan is a large heterocyclic amino acid essential for metabolism, as well as a substrate for protein synthesis and a precursor of niacin, kynurenine, and quinolinic acid (8).

Currently, there is insufficient evidence regarding the effect of GIn and Trp on blastocyst hatching. For this reason, we carried out a detailed examination of the effect of these two amino acids on blastocyst hatching, expansion and viability. Specifically, the aim of this study was to test the effect of Trp and GIn on murine blastocyst hatching in vitro.

Correspondence: W. Castro, Grupo Reproducción, Sede de Investigación Universitaria, Universidad de Antioquia, Calle 62 \#52-59,

Torre 2, Laboratorio 534, Medellín, Colombia. Fax: +574-210-6470. E-mail: reproduccion@medicina.udea.edu.co

Received October 28, 2010. Accepted June 10, 2011. Available online June 24, 2011. Published August 19, 2011. 


\section{Material and Methods}

\section{Reagents}

M2 medium, hemin, mineral oil, Trp, and GIn were purchased from Sigma (USA), HAM F12 medium was a product of GIBCO-Invitrogen (USA), and equine chorionic gonadotrophin (eCG) and human chorionic gonadotrophin (hCG) from Intervet (Netherlands).

\section{Animals}

Virgin 6- to 8-week-old female BALB/c mice $(\mathrm{N}=30)$ were housed in a standard animal care facility in rooms with a controlled light (12 h light:12 h dark) and controlled temperature $\left(22^{\circ}\right.$ to $\left.24^{\circ} \mathrm{C}\right)$. Food and water were available ad libitum. Superovulation was induced by intraperitoneal injection of 5 IU eCG, followed by 5 IU hCG $48 \mathrm{~h}$ later. The females were then bred overnight with BALB/c males ( $N$ $=10$ ) of proven fertility and checked for the presence of vaginal plugs the next morning. Mating was assumed to have occurred at midnight, which was taken as time zero. The current study was approved by the Animal Research Committee of the University of Antioquia (approval No. 18, January 28, 2005), Medellín, Colombia, and conducted according to the Guidelines for the Care and Use of Laboratory Animals of the University of Antioquia.

\section{Blastocyst collection and culture}

Mice were sacrificed using a $\mathrm{CO}_{2}$ chamber and the uterine cornua were immediately isolated (one every $5 \mathrm{~min}$ ) 3.5 days postcoitus (96-98 h after hCG injection). The uterine cornua were handled under the dissecting microscope with surgical tweezers. A 12-inch needle with a 1-mL syringe was introduced into the lumen of the uterus and blastocysts inside the uterine cornua were flushed out into Petri dishes (Falcon, USA) with $3 \mathrm{~mL}$ HAM F12 medium. The Petri dishes were incubated for $30 \mathrm{~min}$ to allow the blastocysts to sediment. The blastocysts were then washed twice in 20- $\mu \mathrm{L}$ droplets of prewarmed M2 medium. The embryos were cultured bars $=10 \mu \mathrm{m}$. in groups of 3 embryos per well in 96-well dishes (Nunc, USA) in $150 \mu \mathrm{L}$ M2 medium and overlaid with $50 \mu \mathrm{L}$ mineral oil. Embryos were stimulated either with $\mathrm{M} 2$ medium containing $0.125,0.25$, or $0.5 \mathrm{mM}$ Trp plus $0.2 \%$ hemin, or M2 medium supplemented with $1 \mathrm{mM}$ Gln, or M2 medium alone as control. These concentrations of Trp and GIn are optimal for in vitro culture of mouse embryos $(3,9)$. The effect of GIn and Trp on embryo development was compared to that of M2 medium alone. Each experiment was performed in triplicate and observations were made every $24 \mathrm{~h}$ for $72 \mathrm{~h}$. The blastocysts $(\mathrm{N}=262)$ were divided as follows: $\mathrm{M} 2$ alone $(\mathrm{N}=60), 0.125 \mathrm{mM} \operatorname{Trp}(\mathrm{N}=27), 0.25$ $\mathrm{mM} \operatorname{Trp}(\mathrm{N}=96), 0.5 \mathrm{mM} \operatorname{Trp}(\mathrm{N}=28)$, and $1 \mathrm{mM} \operatorname{Gln}(\mathrm{N}$ $=51$ ), respectively.

\section{Assessment of blastocyst morphology}

Embryo morphology was determined after 24, 48, and $72 \mathrm{~h}$ of culture using an inverted phase-contrast microscope (magnification: 10 and 40X). Embryo morphology was classified according to the following criteria: Blastocyst (Figure 1A): embryos with an intact ZP, a flat trophoectoderm, a protuberant ICM, and an expanded blastocele; hatched blastocyst (Figure 1B): embryos that protruded partially or

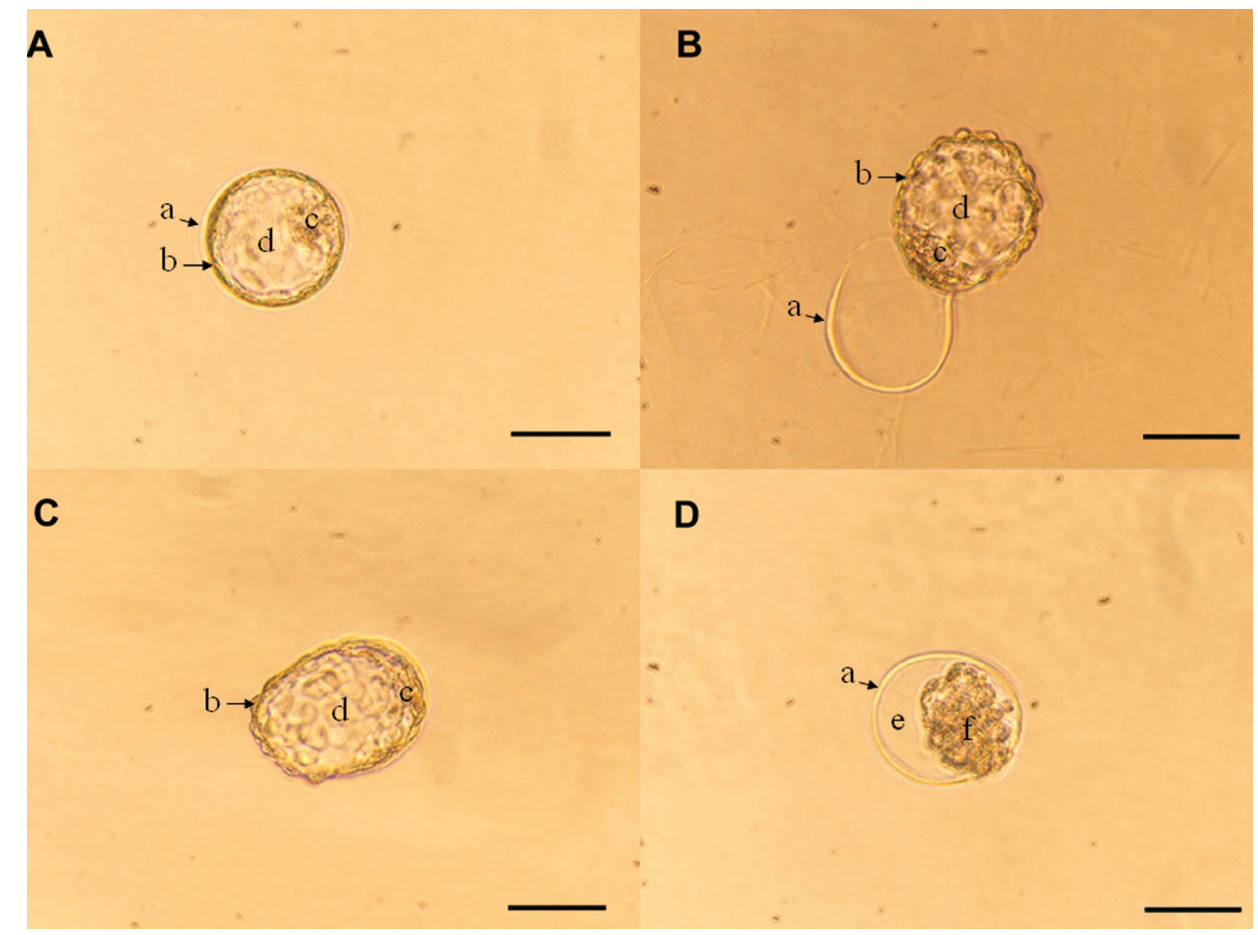

Figure 1. Murine blastocyst development. A, Blastocyst: embryos with an intact zona pellucida (ZP; a), a flat trophoectoderm (b), a protuberant inner cell mass (c), and an expanded blastocele (d). $B$, Hatched blastocyst: embryos that protruded partially or completely from the ZP. C, Expanded blastocyst: hatched blastocysts with an increase in diameter compared to the blastocyst or hatched blastocyst stages. $D$, Degenerated blastocyst: either unexpanded embryos with a space (e) between the trophoectoderm and the ZP, or embryos with cell fragmentation (f). Magnification: 10X. Scale 
completely from the ZP; expanded blastocyst (Figure 1C): hatched blastocysts with an increase in diameter compared to the blastocyst or hatched blastocyst stages; degenerated blastocyst (Figure 1D): either unexpanded embryos with a space between the trophoectoderm and the ZP, or embryos with cell fragmentation.

\section{Statistical analysis}

The experiments were performed three times in triplicate, and the results are reported as the mean \pm SEM of each experiment. One-way ANOVA with the Tukey multiple comparison post-test was used to compare the different stimuli. $\mathrm{P} \leq 0.05$ was considered to be significant.

\section{Results}

\section{Hatched blastocysts}

The percentage of hatching at $24 \mathrm{~h}$ in the group of blastocysts stimulated with GIn (100\%) was significantly higher than M2 medium alone (21.1 $\pm 8.4 \%), 0.25 \mathrm{mM}$ $\operatorname{Trp}(36.7 \pm 10.7 \%)$ or $0.5 \mathrm{mM}$ Trp $(22.2 \pm 11.1 \%$; $\mathrm{P}<$ 0.05 ; Figure 2A). In the group of embryos stimulated with 0.125 or $0.25 \mathrm{mM}$ Trp, the percentage of hatching was higher than in M2 alone (Figure 2A). At 48 h of culture, the percentage of hatching in the groups stimulated with Trp was higher compared to the hatching at $24 \mathrm{~h}$ (Figure 2B). The blastocysts maintained without amino acids or with $0.25 \mathrm{mM}$ Trp gradually reached their highest percentage of hatching at $72 \mathrm{~h}$ (Figure 2C), whereas blastocysts cultured with GIn reached their highest percentage of hatching at $24 \mathrm{~h}$ (Figure 2A). After $48 \mathrm{~h}$, blastocyst hatching was lower in the groups cultured with 0.125 and $0.5 \mathrm{mM}$ Trp as compared to the result observed in the groups of blastocysts maintained in $\mathrm{M} 2$ alone or supplemented with $0.25 \mathrm{mM}$ Trp (Figure 2C).

\section{Expanded blastocysts}

Blastocyst expansion was observed after $48 \mathrm{~h}$ of culture and was significantly higher in the group of blastocysts cultured with GIn (66.6 $\pm 0.2 \%)$, compared to either M2 alone $(9.7 \pm 7.9 \%), 0.25 \mathrm{mM} \operatorname{Trp}(19.1 \pm 6.1 \%)$ or $0.5 \mathrm{mM}$ $\operatorname{Trp}(7 \pm 3.5 \%$; $\mathrm{P}<0.05$; Figure $3 \mathrm{~A})$. Moreover, the percentage of expanded blastocysts was significantly higher in the presence of $0.125 \mathrm{mM} \operatorname{Trp}(61.1 \pm 16.0 \%)$ compared to $\mathrm{M} 2$ alone or to $0.5 \mathrm{mM} \operatorname{Trp}(\mathrm{P}<0.05$; Figure $3 \mathrm{~A})$, and was similar to the group stimulated with GIn (Figure $3 A$ ). After $72 \mathrm{~h}$ of culture, the expansion of the blastocysts increased to $96.2 \pm 2.1 \%$ in the group of blastocysts stimulated with GIn compared to expansion at $48 \mathrm{~h}$ (Figure 3B). No statistically significant differences were observed in the groups stimulated with Trp compared to M2 alone (Figure 3B). These results show that treatment with Gln or $0.125 \mathrm{mM}$ Trp after hatching could be useful to increase the rate of expanded blastocysts.
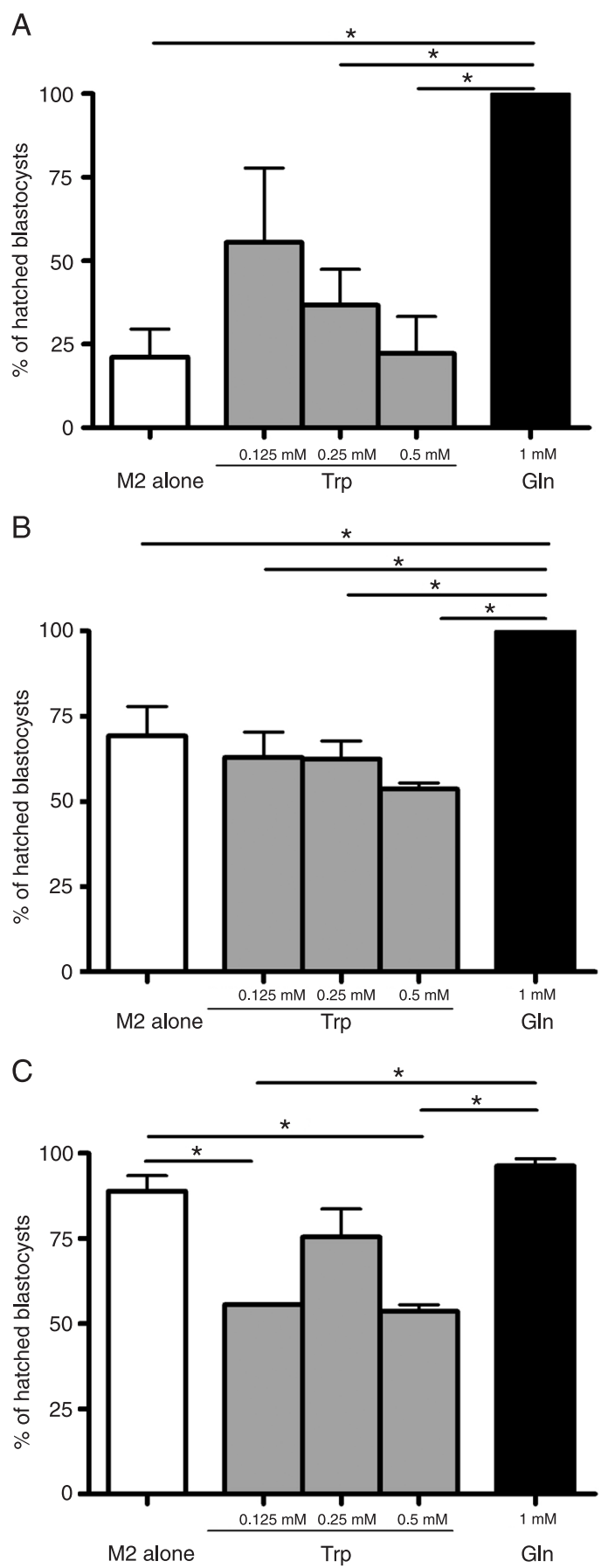

Figure 2. Induction of blastocyst hatching by Gln. The figure shows the percentage (means \pm SEM) of hatched blastocysts at 24,48 , and $72 \mathrm{~h}$ of incubation in M2 medium alone (open bar), or medium plus $0.125 \mathrm{mM}$ Trp, $0.25 \mathrm{mM}$ Trp, $0.5 \mathrm{mM}$ Trp (gray bars), or $1 \mathrm{mM}$ Gln (black bar). Hatching of the blastocysts cultured in M2 medium containing $1 \mathrm{mM}$ Gln was significantly higher than in the other conditions at 24 (A) and $48 \mathrm{~h}$ (B). Embryo hatching did not increase in the groups stimulated with 0.125 and $0.5 \mathrm{mM}$ Trp at $72 \mathrm{~h}(\mathrm{C})$ compared to $48 \mathrm{~h}$. ${ }^{*} \mathrm{P}<0.05$ (one-way ANOVA). 


\section{Degenerated blastocysts}

The percentage of degenerated blastocysts was determined after $48 \mathrm{~h}$ of culture. The lowest percentage of degenerated blastocysts was observed in groups cultured with $\mathrm{GIn}(0 \%)$, M2 alone $(2.7 \pm 2.7 \%)$ and $0.25 \mathrm{mM} \operatorname{Trp}(6.1$ $\pm 1.4 \%$; Figure 4A). Unexpectedly, the highest percentage of degenerated blastocysts was obtained in groups of blastocysts stimulated with 0.5 or $0.125 \mathrm{mM}$ Trp compared to $\mathrm{M} 2$ alone or GIn (Figure 4A). After $72 \mathrm{~h}$ of culture, the percentage of degenerated blastocysts increased to $16.1 \pm$ $6.2 \%$ with $0.25 \mathrm{mM}$ Trp, to $67.7 \pm 6.5 \%$ with $0.5 \mathrm{mM}$ Trp and it increased drastically in the group stimulated with 0.125 $\mathrm{mM}$ Trp, reaching $48.1 \pm 19.5 \%$ (Figure 4B). After $96 \mathrm{~h}$ of

A
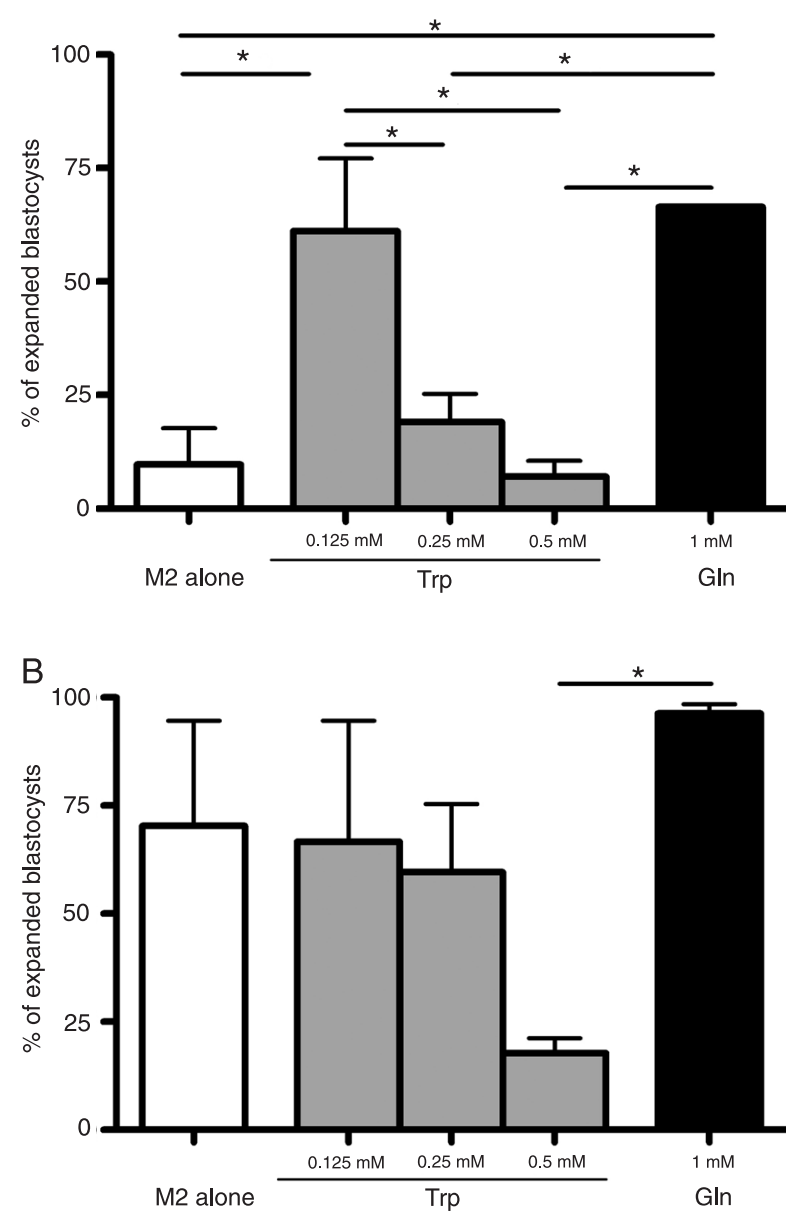

Figure 3. Effect of Trp and GIn on blastocyst expansion. The figure shows the percentage (means \pm SEM) of expanded blastocysts at 48 and $72 \mathrm{~h}$ of incubation in M2 medium alone (open bar), or medium plus $0.125 \mathrm{mM}$ Trp, $0.25 \mathrm{mM}$ Trp, $0.5 \mathrm{mM}$ Trp (gray bars), or $1 \mathrm{mM} \mathrm{Gln}$ (black bar). The expansion of the blastocysts cultured in the medium containing $1 \mathrm{mM}$ GIn or $0.125 \mathrm{mM}$ Trp was significantly higher than in the other conditions at $48 \mathrm{~h}$ (A); expansion of the blastocysts at $72 \mathrm{~h}$ was highest in the medium containing $1 \mathrm{mM}$ GIn (B). ${ }^{*} \mathrm{P}<0.05$ (one-way ANOVA). culture the percentage increased in all groups except the group with GIn (data not shown). Overall, blastocyst viability was preserved until $72 \mathrm{~h}$ in the groups cultured with $\mathrm{M} 2$ alone, $0.25 \mathrm{mM}$ Trp, or GIn (Figure 4). On the other hand, 0.125 and $0.5 \mathrm{mM}$ Trp had a detrimental effect on embryo viability beyond $48 \mathrm{~h}$ of culture.

\section{Discussion}

In addition to rupture of the ZP by the expanding blastocyst or proteases, blastocyst hatching also requires dynamic changes in the cytoskeleton (1). These cytoskeletal changes occur during hatching because the trophoectoderm
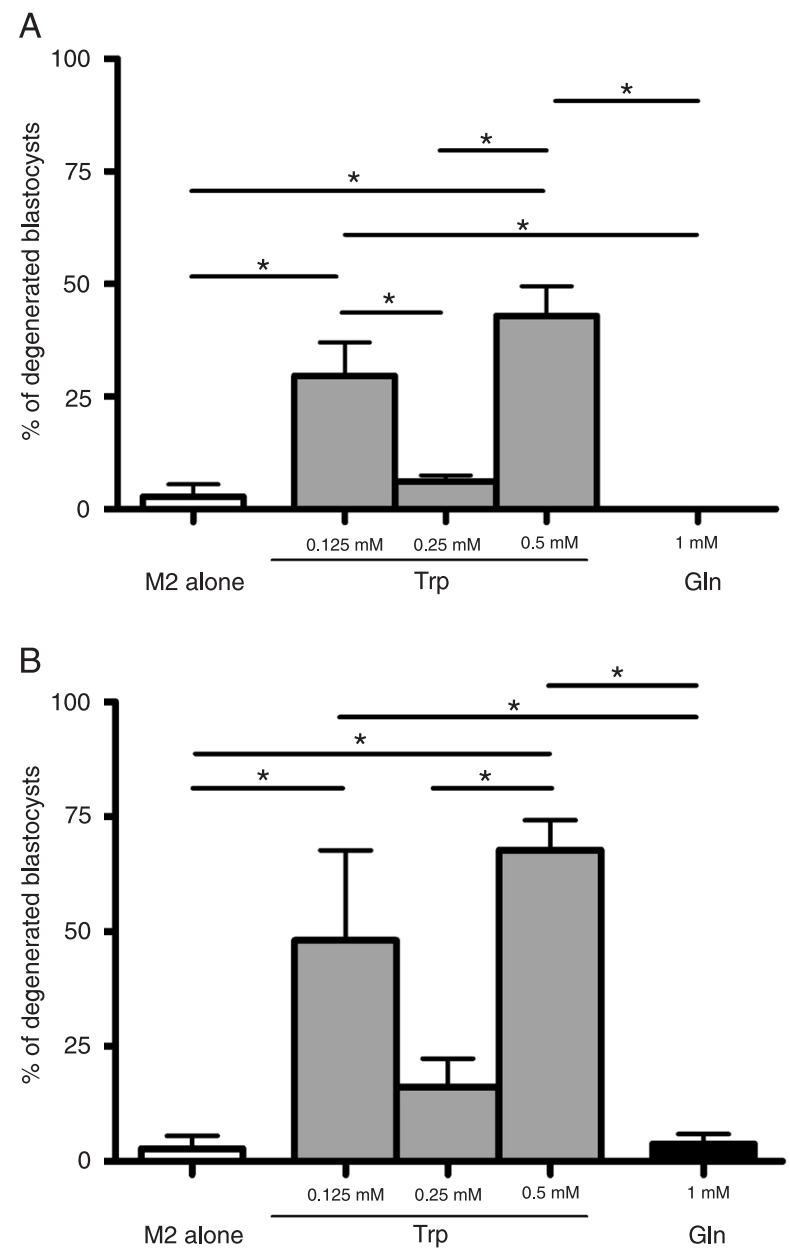

Figure 4. Blastocyst viability is preserved by Gln. The figure shows the percentage (means \pm SEM) of degenerated blastocysts at 48 and $72 \mathrm{~h}$ of incubation in M2 medium alone (open bar), or $0.125 \mathrm{mM} \operatorname{Trp}, 0.25 \mathrm{mM} \operatorname{Trp}, 0.5 \mathrm{mM}$ Trp (gray bars), or $1 \mathrm{mM}$ Gln (black bar). The degeneration of blastocysts cultured in M2 medium containing $1 \mathrm{mM}$ Gln or M2 alone was significantly lower than in the other conditions at $48(\mathrm{~A})$ and $72 \mathrm{~h}(\mathrm{~B}) .{ }^{*} \mathrm{P}<0.05$ (one-way ANOVA). 
protrudes through a narrow hole in the ZP, which allows the entire blastocyst to escape from the ZP. This process may imply complex signaling mechanisms orchestrated by amino acids, growth factors and cytokines. In this study, we show that GIn may positively modulate blastocyst protrusion from the ZP, inducing $100 \%$ hatching after $24 \mathrm{~h}$. GIn is involved in different cell signaling pathways, suggesting that it has the potential to determine distinct cell fates, including growth, differentiation and death (10).

In order to characterize other possible actions of GIn and Trp, we determined blastocyst viability and observed that GIn, but not Trp, prevented blastocyst degeneration at all times; whereas Trp had a detrimental effect at 48 $\mathrm{h}$ that was maintained until $72 \mathrm{~h}$ of culture. This result is consistent with previous studies showing the influence of Gln on mouse embryo development in vitro $(11,12)$. For this reason, we propose that GIn has a protective effect on embryo development in vitro.

When the embryos were cultured in M2 medium with Trp, we observed an increase in the percentage of degenerated blastocysts at $72 \mathrm{~h}$. However, we could not explain why $0.25 \mathrm{mM}$ Trp did not have a defined detrimental effect as was observed with 0.125 and $0.5 \mathrm{mM}$ Trp. Although the experiments were performed three times in triplicate, we always observed the same pattern of viability with 0.25 $\mathrm{mM}$ Trp. Moreover, the low dispersion of the data did not indicate variations between experiments. Further experiments are required to explain why $0.25 \mathrm{mM}$ Trp had this unexpected effect.

Initially, we hypothesized that Trp would play an important role during embryo development. Indeed, $0.125 \mathrm{mM}$ Trp promoted blastocyst expansion after $48 \mathrm{~h}$. Van Winkle et al. (13) have described in detail the $\mathrm{B}^{0,+}$ system, an

\section{References}

1. Niimura S, Fujii M. A morphological study of blastocyst hatching in the mouse and rat. J Reprod Dev 1997; 43: 295302.

2. De Vos A, Van Steirteghem A. Zona hardening, zona drilling and assisted hatching: new achievements in assisted reproduction. Cells Tissues Organs 2000; 166: 220-227.

3. Rezk Y, Huff C, Rizk B. Effect of glutamine on preimplantation mouse embryo development in vitro. Am J Obstet Gynecol 2004; 190: 1450-1454.

4. Devreker F, Hardy K. Effects of glutamine and taurine on preimplantation development and cleavage of mouse embryos in vitro. Biol Reprod 1997; 57: 921-928.

5. Du ZF, Wales RG. Some effects of genotype and composition of the culture medium on the development of mouse zygotes in vitro. Reprod Fertil Dev 1993; 5: 405-415.

6. Summers MC, Biggers JD. Chemically defined media and the culture of mammalian preimplantation embryos: historical perspective and current issues. Hum Reprod Update 2003; 9: 557-582.

7. Spindle AI, Pedersen RA. Hatching, attachment, and out- amino acid transporter in murine embryos that regulates the entry of Trp, leucine, isoleucine, and phenylalanine into the blastocysts. It is clear from our results that $0.125 \mathrm{mM}$ Trp promotes blastocyst expansion during the first $48 \mathrm{~h}$, whereas higher Trp concentrations have no effect. This fundamental action of Trp at low concentrations might reflect certain requirements of the embryo, such as its expansion under physiological conditions in vivo during the preimplantation period. It is possible that such a phenomenon occurs, based on the findings of Harris et al. (14) and Hugentobler et al. (15) who observed that Trp, methionine and asparagine were present at low concentrations in murine (14) and bovine (15) reproductive tracts compared to other amino acids. Thus, we conclude that $0.125 \mathrm{mM}$ Trp has a positive effect on the percentage of expanded blastocysts just after hatching, but a detrimental effect prior to hatching.

We showed in this study that GIn induces blastocyst hatching and preserves embryo viability. Furthermore, both GIn and $0.125 \mathrm{mM}$ Trp regulate blastocyst expansion. Therefore, we suggest that supplementation of the culture medium with GIn is useful to improve embryo development in vitro.

\section{Acknowledgments}

Research supported by a grant from "Comité para el Desarrollo de la Investigación” (CODI), University of Antioquia, Medellin, Colombia, and by Colciencias (grant\#111505-11491). We are grateful to Anne-Lise Haenni (Institut Jacques Monod, Paris, France) for a careful reading of the manuscript. We also thank Juan Guillermo Maldonado Estrada (Coordinator of the Centauro Group, University of Antioquia) for his comments about this manuscript. growth of mouse blastocysts in vitro: fixed nitrogen requirements. J Exp Zool 1973; 186: 305-318.

8. Tatsumi K, Higuchi T, Fujiwara H, Nakayama T, Egawa $\mathrm{H}$, Itoh $\mathrm{K}$, et al. Induction of tryptophan 2,3-dioxygenase in the mouse endometrium during implantation. Biochem Biophys Res Commun 2000; 274: 166-170.

9. Lane M, Hooper K, Gardner DK. Effect of essential amino acids on mouse embryo viability and ammonium production. J Assist Reprod Genet 2001; 18: 519-525.

10. Newsholme P, Procopio J, Lima MM, Pithon-Curi TC, Curi R. Glutamine and glutamate - their central role in cell metabolism and function. Cell Biochem Funct 2003; 21: 1-9.

11. Biggers JD, McGinnis LK, Lawitts JA. Enhanced effect of glycyl-L-glutamine on mouse preimplantation embryos in vitro. Reprod Biomed Online 2004; 9: 59-69.

12. Summers MC, McGinnis LK, Lawitts JA, Biggers JD. Mouse embryo development following IVF in media containing either L-glutamine or glycyl-L-glutamine. Hum Reprod 2005; 20: 1364-1371.

13. Van Winkle LJ, Tesch JK, Shah A, Campione AL. System 
$\mathrm{B}^{0,+}$ amino acid transport regulates the penetration stage of blastocyst implantation with possible long-term developmental consequences through adulthood. Hum Reprod Update 2006; 12: 145-157.

14. Harris SE, Gopichandran N, Picton HM, Leese HJ, Orsi NM. Nutrient concentrations in murine follicular fluid and the female reproductive tract. Theriogenology 2005; 64: 992-1006.

15. Hugentobler SA, Diskin MG, Leese HJ, Humpherson PG, Watson T, Sreenan JM, et al. Amino acids in oviduct and uterine fluid and blood plasma during the estrous cycle in the bovine. Mol Reprod Dev 2007; 74: 445-454. 